\title{
BIM-GIS Community of Practice
}

\author{
P. A. Corcoran ${ }^{1}$, D. A. Bruce ${ }^{1}$, A. Elmualim ${ }^{1}$, D. Fong ${ }^{2}$, \\ T. McGinley ${ }^{2} \&$ B. Stephens ${ }^{3}$ \\ ${ }^{1}$ School of Natural and Built Environments, \\ University of South Australia, Australia \\ ${ }^{2}$ School of Art, Architecture and Design, \\ University of South Australia, Australia \\ ${ }^{3}$ Facilities Management Unit, \\ University of South Australia, Australia
}

\begin{abstract}
The digital recording of spatio-temporal information within Building Information Modelling (BIM) and Geographical Information Systems (GIS) has mainly been the preserve of experts, but with the advent of more user friendly technologies, more non-spatio-temporal information experts are beginning to realise the benefits that the use of spatio-temporal information can bring.

A burgeoning area of interest has been the technological interface between BIM and GIS but allied to this are the collaborative interests of the people, who exhibit varying levels of BIM-GIS exposure, involved with such developments. A selection of staff at the University of South Australia (UniSA) developed a collaborative exercise to introduce BIM and GIS into university business processes with a view to incorporating more use within the Facilities Management Unit (FMU), whilst simultaneously widening the role of spatio-temporal information in both teaching and research.

The participants decided to operate within a Community of Practice (CoP) i.e. an arena that provides both a context and environment where people can come together to share ideas, talk about practices and learn together. On reflection, the participants thought a $\mathrm{CoP}$ was a suitable vehicle to explore BIM-GIS collaboration and through this discovered that, although they had differing standpoints in relation to the perceived interface between BIM and GIS, they shared similar aspirations as to the usefulness of BIM and GIS working together. There have been issues to address e.g. finding time to participate in the CoP, but
\end{abstract}


nevertheless, through the creation of wayfinding project, the $\mathrm{CoP}$ aims to showcase and expand BIM-GIS collaboration into other areas of university. Keywords: collaboration, university, spatio-temporal information.

\section{Introduction}

Location and time are significant factors for many businesses. Building Information Modelling (BIM) and Geographical Information Systems (GIS) have enabled the efficient digital portrayal of spatio-temporal information and consequently opened up new analytical possibilities for such businesses, thus increasing the importance of such contemporary technologies in modern societies. Although it can be inferred, through the writings of Bergin [1] and Tomlinson [2], that BIM and GIS had similar origins, epochs and founders during the 1960s, the systems have diverged somewhat into separate industries. However, with the development of disruptive technologies, such as Google Earth, many more people are engaging with spatio-temporal technologies (Corcoran [3]) and consequently being exposed to the inherent opportunities that engaging with spatio-temporal information presents. Nevertheless, there are still many businesses that do not maximise the use of spatio-temporal information for competitive advantage: to become more visible to such entities it could be worthwhile for those involved with BIM and GIS to consider working more collaboratively, thereby generating some economies of scale to expose even further the benefits that using spatiotemporal information can bring.

Within this ideal of cooperation, educators could have a pivotal role due to their position in educating and influencing the future spatio-temporal information leaders. However, as with other industries, the education sector needs to operate within political and fiscal restraints, and consequently expansion of such worthwhile endeavours would have to be undertaken as efficiently as possible. To this extent, the use of a Community of Practice (CoP) is potentially beneficial, as such an informal forum engenders an egalitarian environment where, as Wenger [4] noted, volunteers mutually engage on a joint enterprise and use their shared repertoire. Such a gathering of personnel began in 2014 at the University of South Australia (UniSA), where a CoP involving representatives from the Facilities Management Unit (FMU) met with academics from Architecture, Construction and Geospatial to explore BIM-GIS collaboration. Introducing, developing and expanding a $\mathrm{CoP}$ into a BIM-GIS collaborative environment though, could pose issues due to the participants' differing standpoints and aspirations and consequently these may need to be addressed to ensure successful collaboration efforts. This paper documents the development of this BIM-GIS CoP and progresses onto how the members believed the $\mathrm{CoP}$ would expand its scope, activities, and impact in the future.

\section{Background}

Whilst the fundamental building blocks of technologies such as BIM and GIS are similar, the terminologies, applications and 'ownership' of these are often 
misunderstood and frequently contested. Fundamental components of BIM and GIS consist of relational data bases, geometric description of objects and their positions in space, time-stamping, visualization and a set of analytical techniques which enable the user to ask spatio-temporal questions and model scenarios. What connects the two technologies is space, time and, of course, computers. Modern GIS had its origins in the 1960s when computers were applied to 2D representations of various aspects of geography (Foresman [5]). The third dimension was, and largely still is, managed as an attribute attached to a 2D location. Information in databases was attached to the geometric primitives of points, lines, polygons and cells; only in a few GIS systems did the geometric primitive extend to volumes and the database include time as a primary coordinate. Whilst GIS primitives have evolved with information now attached to objects, much of the spatial reasoning and modelling is affected by the developmental history. Interestingly, BIM has its origins in similar timeframe to GIS and even shares an early founder - Ian McHarg (Bergin [1]). However, the focus on computerisation of architectural drawings and building objects through features such as the Building Description System (BDS), which embedded building information in databases, saw the two technologies diverge somewhat. The essential focus in BIM on 3D also differentiated it from GIS and finally, a real difference in reference systems means that in the modern versions of the technologies there are some alternative approaches to very similar issues. With respect to geometric reference systems, the GIS world utilizes $\mathrm{X}, \mathrm{Y}, \mathrm{Z}$ or (longitude, latitude, height) coordinates relative to the centre of the Earth which is defined by a geographical datum. These coordinates are projected into 2D map projection coordinates (East, North) and Z, relative to a difficult to define vertical datum, is added as an attribute. Whereas, in BIM, geometric reference systems are frequently local, either to individual building objects or to building sites. In essence, it could be argued that GIS is the 'outside' world whereas BIM is 'inside'. Both technologies make strong use of topological mathematics in spatial analysis, but in general the two differ in relation to the way in which time is encoded and analysed. Given the common origins yet different histories, contemporary users of the two technologies, who plan to work collaboratively, face some interesting challenges, especially when the technologies are to be utilized by a diverse group of professionals.

During the past four decades there was an ambition in social science and engineering towards multi and interdisciplinary research. However, there was criticism of such research approaches. According to Maruyama [6] social scientists were actively, and only reading and citing each other's work, ignoring the reality of belonging to a borderless crowd of humans exploring the same reality. This has led to research work staying within a limited space due to accreditation and professional certification (Maruyama [6]). In the built environment, this can only serve to insulate researchers from one another. Maruyama [6] argued for researchers to go outside the comfort of one's own discipline and immerse oneself in the various concepts, theories and research methodologies of other disciplines. This was seen as the way forward for advancing a robust research in the built environment to meet societal needs. 
However, the built environment is a complex social-ecological system where multiple actors interact at different scales and various times (Moffat and Kohler [7]). Contrary to this assertion, the research in the built environment is still being produced in silos due to the various forms of protectionism and professional certification. Hence, existing theories and methods are not capable for integrating the complexity of the built environment in terms of spatial and physical, social and time relationships. However, the advancement of various digital technologies practices are paving the way for integrative methods for the built environment research such as BIM and GIS. 'While all the methods are challenged with methodological problems, it is also true that considerable progress appears to have occurred in that last few years, and that practical tools may soon emerge for use in daily practice' (Moffat and Kohler [7]). In order to overcome the negative cultural aspects of the silos research in the built environment, new concepts and frameworks for socially integrating research teams, groups and organisations are needed to harness the possibilities offered by the unprecedented advancement of digital technologies. It is argued in this paper that the application of the concept of $\mathrm{CoP}$ could provide the platform to support an integrative transdisciplinary research in the built environment.

\section{Community of Practice}

CoP theory provides a system for comprehension of the complex social basis of knowledge management and development (Wenger et al. [8]). The concept gives organisations the ability to utilise their people and knowledge base to their fullest extent achieving a persistent competitive advantage. Pfeffer [9] stated that knowledge sharing is essential for the functioning of any CoP. The complexity and fragmentation of the built environment makes communities of practice particularly applicable.

A CoP can be described as 'groups of people who share a concern or passion for something they do, and learn how to do it better as they interact regularly' (Wenger [4]). A CoP is closely linked to situated learning, where by learning is continuous and dependent on the environment in which it takes place and looks to surpass previous thinking that learning is the end point of knowledge transmission (Lave and Wenger [10]). Situated learning leads to the immersion of the learner in their subject which is known as 'legitimate peripheral participation' (Wenger [11]). Changing participation and identity within the CoP is an important factor for as a new community member becomes acquainted with the manner in which the community operates and accumulates knowledge, they progress from the practice fringes to its centre. 'Participation shapes not only what we do, but also who we are and how we interpret what we do' (Elmualim and Govender [12]) so learning as a fundamentally social process must be integral with social participation (Peltonen and Lamsa [13]).

The fundamental difference between communities of practice and the research teams and task groups commonly found within the industry is that the group is linked via knowledge rather than a job. Consequently, such communities are bound by the learning they have engaged in rather than their venture and it is the 
knowledge contained within the community that makes being part of it valuable (Wenger [4]). The benefits of communities of practice within research are wide ranging, facilitating creation, accumulation and diffusion of knowledge. Work can be achieved quicker and with a higher degree of competence within a dynamic, evolving environment (Wenger [4]). However, the organic dynamism associated with communities of practice makes them difficult to manage or create artificially; nevertheless they function best when allowed to work without management, to innovate and adapt (Peltonen and Lamsa [13] and Wenger et al. [8]). However, research has shown that a top down managerial approach to communities of practice can be used, providing it doesn't prevent knowledge being the group's central binding force as opposed to task or objective (Thompson [14]). Alongside the very positive influence communities of practice can have, it should be noted that their intrinsic social structure can lead to conflict caused by an unequal distribution of power. New members entering the community have potential to upset dynamics due to a lack of consensual knowledge and divergent sense of identity (Hislop [15]). A further criticism and pitfall to avoid is the unwarranted transition of the community into a 'group think' where all members are trying to conform to set of socially implicit research rituals (Elmualim and Govender [12]).

\section{Development of the UniSA Community of Practice}

The UniSA BIM-GIS collaborative CoP first met in 2014 and initial dialogue surrounded the background to each of the members' area of interest, their understanding of both BIM and GIS and their aspirations in regards to this collaborative working environment, and finally, discussion as to any apprehensions and difficulties in relation to engaging across a multi-disciplinary environment. Each discipline (i.e. Architecture, Construction, Facilities Management and Geospatial) detailed their standpoints and aspirations.

\subsection{Architecture: standpoints and aspirations}

Architecture believed that the use of BIM at the earliest stages of design, could not only inform the design process, but could ultimately aid deciphering the running costs of buildings over their lifetime. However, an architect's perspective on the BIM-GIS model was constrained by the scope of their involvement in the lifecycle of buildings. For instance, whilst the as built model was an essential from the Facilities Management (FM) perspective, it was normally not produced by the architect. It was thought that one way to view these different perspectives on the models in the lifecycle of buildings was through the Level of Detail (LOD) stages of BIM (Figure 1). Consequently, it was felt that BIM LOD could provide a frame to discuss enhancing $\mathrm{CoP}$ stakeholder perspectives on the use of BIM and GIS in the design, construction, maintenance and operation of buildings. With this in mind, it was interpreted that that BIM and GIS both were essentially similar asset oriented information systems. However, it was felt that there was a scale difference between the two information systems and as such, GIS could be seen as BIM LOD 000 or LOD 100. Viewed in this way, GIS could be viewed as a subset of BIM. 


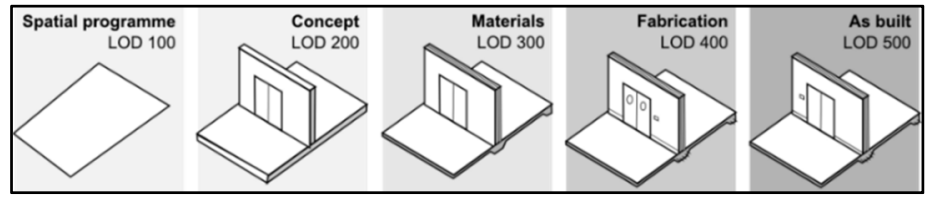

Figure 1: $\quad$ BIM LOD (McGinley [16]).

Architecture regarded this $\mathrm{CoP}$ as an exciting opportunity as it pointed to a centralised and contextual information system for buildings that could enable the development of other approaches such as mapping user behaviour on to the as built model so that it could be analysed in future designs (McGinley and Fong [17]). Architecture thought that a BIM collaborative approach was vital and could ultimately offer the ability to map building typology through its usage by the occupants to the BIM-GIS model. Consequently, the design of buildings could be formally influenced by both client based programming requirements and previous use data and case based reasoning (Aamodt and Plaza [18]). The ability to generate a typology of building usage to inform future design was highlighted as being invaluable for the design and would also inform the maintenance cost of buildings over their lifetime. The use of Post Occupancy Evaluation (POE) data over the lifetime of buildings to capture occupancy traffic, services utilisation, power etc. was considered to not only serve current buildings, but future buildings of its type.

\subsection{Construction: standpoints and aspirations}

Construction and project management has been seen as applied science. It had been argued that most of the research in the field of construction was a derivative from other disciplines, such as management and management science, organisation theory, physics, building and indeed computer science and system engineering. Together with the nature of construction as a project based industry, this positioned the industry well to take advantage of the new technological development such as BIM and GIS. However, the reality of the industry was contrary to that due to its fragmentation and the wide criticism of the lack of collaboration amongst its' participating actors. The fragmentation was one of the reasons for the acclaimed poor performance of the industry, worldwide. There were mounting calls for the industry to change and embrace collaborative working practices specially in integrating the facilities management processes into the design and construction.

It was envisaged that digital technologies such as BIM would enable the transformation of the industry through the adoption of collaborative working practices. While social challenges have been posed in embracing collaborative working, BIM was seen as enabler to that desired change and thus allow the industry to deliver high performance on projects in all financial, time and quality terms. This CoP project in particular, was seen by Construction as initiation to further advance the sustainable management of built environments, not only on a building by building basis but rather to include neighbourhood, precinct and city levels. There were considerable implications of such aspirations in terms of 
education and research. An integrative approach to research and education were seen as vital to attain those aspirations, advocating inter and transdisciplinary research work for the development of smart and sustainable built environments.

\subsection{Facilitates management unit: standpoints and aspirations}

Location has always been a key element in the management approach of UniSA's FMU, informing management strategies and operational decisions. For example, location has been inherent in FMU's site maintenance, asset management, lease management, space management, construction project management, energy and water management, cleaning, parking and security/access management. FMU has explored the potential of both BIM and GIS and their respective abilities to integrate the capture of not just the location and geography of things, but also the relationships between them, to offer opportunities for more comprehensive FM capability. Eliminating information silos and considering information holistically was viewed as providing the potential to reveal previously undiscovered relationships and patterns in data, resulting in greater insight and therefore more effective management strategies.

FMU's interest in BIM resided in its representation of both the physical and functional characteristics of a building. BIM's richness of information was viewed as a method to increase both users' and managers' understanding of a building and its interrelationships, thus greatly increasing the ability to understand the impact of changes and problem solve issues. It was hoped that using BIM as a management information tool would increase the likelihood of predictable building performance and the opportunity for a 'whole of life' approach, thus maximising efficiency and minimising expenditure over a building's lifecycle. However, FMU faced challenges in ways to convince key decision makers as to the benefits of both BIM and GIS. FMU viewed the $\mathrm{CoP}$ as an opportunity to get visibility and traction in these areas outside the immediate FMU environment, to the wider university environment. FMU welcomed the opportunity to utilise the university's research expertise and the opportunity to foster collaboration.

\subsection{Geospatial: standpoints and aspirations}

Geospatial initially believed that with the inherent spatio-temporal nature of GIS, BIM was a particular strand of a GIS, or more appropriately a part of GIS without the 'Geo' prefix i.e. a Spatial information Systems (SIS). Indeed, many institutions in Australia utilise such phraseology in the programs they teach (Corcoran and Bruce [19]). Furthermore, the traditional graphical output from the profession i.e. a map, has the definition of a graphical representation of spatial relationships (Robinson [20]) - a definition that could equally be applied to a BIM. Initially, Geospatial observed that GIS was perceived by some members the CoP as related to 'geographic objects' which were relatively large in size and that it was not appreciated that GIS was used at all scales, from sub mm to planetary. However, on reflection within the $\mathrm{CoP}$, the more overarching viewpoint came to the fore in that it was probably not a matter of BIM versus GIS, or even BIM and GIS, rather it was more that both of these areas existed within 'spatio-temporal' environment. 
The visibility in the use of GIS within Australia is problematical, a stance emphasized by continuing low tertiary education enrolments (McDougall et al. [21]), and consequently the Australian spatial industry needs a boost. The spatial community is still relative young industry and as such, does not possess the weight in numbers to push through its worth. Therefore, Geospatial hoped by collaborating in this CoP, and as such working with Construction, FMU and Architects, the 'sum of the whole would be greater than the parts'. Furthermore, the prominence of BIM and the importance of the construction industry to the Australian economy could serve as a catalyst for increased use of GIS. In addition, Geospatial aspired to the total integration of spatial information from all buildings, underground assets, between building objects (car parks, roads, paths, trees, drinking fountains, gates, signs, etc.), telecommunication routes, and so on.

\section{Discussion}

\subsection{Development}

From the standpoints and aspirations of the CoP members, it can be interpreted that the $\mathrm{CoP}$ has developed for a common cause, and thus reinforced the belief that CoPs can lever organisational ability to utilise their people and knowledge base to their fullest extent. Each of the areas had different skillsets and ideas about BIMGIS interaction that alone would have not produced significant competitive advantage. The CoP has reflected the notion about passionate people coming together from different disciplines to share knowledge regularly, but without being encumbered by strict outcomes or authoritarian regime. Such an outcome reinforces theory that a $\mathrm{CoP}$ is more about enhancing knowledge rather than a coming together to undertake specified tasks.

The CoP member standpoints have developed over time, as knowledge and perspective has been gained about the other disciplines. For example, Geospatial relinquished the perceived 'premier' role that BIM is part of GIS, and moved to stance where BIM and GIS are considered to be integral parts of a bigger spatiotemporal universe. Similarly, Architecture and Construction have widened their scope of BIM being predominantly predicated on building use (the aforementioned 'inside'), to a more holistic view that incorporates the exterior (outside) environment that surround buildings. The $\mathrm{CoP}$ has displayed elements of situated learning, particularly from the incorporation by the BIM advocates (namely Architecture and Construction) of Geospatial and FMU into what could be referred to as a UniSA BIM 'fraternity'. As previously mentioned, the issues associated with GIS use in Australia compared with the increased use of BIM, could quite easily have manifested itself in an 'us and them' scenario, but the positive and inclusive manner in which the $\mathrm{CoP}$ has been conducted has aided the assimilation of the GIS and FMU 'fraternity' to which the CoP members now perceive they possess a spatio-temporal 'fraternity'. The participants continue to regularly interact both inside and outside of the CoP environment. The unity of the CoP has also transcended the hierarchy of its members, who range from junior lecturers through to Professors. As espoused in the literature, it is recommended that there 
is no formal management imposed on a CoP and every member is equal, and this has been displayed thus far on the development of the BIM-GIS CoP. As such, this has also alleviated the concern of uneven distribution of power, and the members are confident that if and when the CoP expands further, these intrinsic values will be upheld on the acceptance of new members.

However, not all the points issued in literature have been realised thus far in the CoP. One such factor is Wenger's [4] idea that work can be achieved quicker in a CoP. Currently, the BIM-GIS CoP is still in its formative stage after nearly a year of operation and this is a frustrating point, which if continued for much longer, could pose more of an issue. By definition, academic life is dominated by research and teaching outputs, and when research time is at a premium and membership of the BIM-GIS CoP is voluntary, there could be tendencies for research to be concentrated in directed, known and own safe areas, thus safeguarding output. Consequently, the opportunity for new exploratory research methods and projects has been restricted. Furthermore, Architecture, Construction, FMU and Geospatial are geographically dispersed around UniSA Campuses, so the opportunity to maintain liquid networks is minimal and as such meetings could benefit from being on a more formal calendar basis rather than an ad-hoc approach.

From a BIM-GIS content perspective, it has been apparent that CoP members have had differing opinions of what BIM is, what GIS is, and what collaboration may mean. In essence such viewpoints have thus far negated any concept of developing the 'group think' scenario noted by Elmualim and Govender [12] as discussion and views are still 'fiercely' discussed. Furthermore, issues arose as to the scale of BIM implementation, i.e. on one side of the spectrum, was an entire rollout of spatio-temporal information across the university and the other end of the spectrum was within the scope of the CoP members' work areas. Due to financial restrictions and political factors e.g. working across different schools and divisions within UniSA, an implementation spanning the whole university was not deemed possible. Therefore, the CoP members decided to build upon their new knowledge and understanding and trial a pilot project focussing on a specific topic that could collaboratively utilise the skills base of the entire membership.

Consequently, the CoP decided to design, build and showcase a university wayfinding tool that could combine the outdoor environment (i.e. GIS focussed) with the more indoor environment (BIM focussed). Such a tool could have multiple benefits to FMU such as (a) Improved student, staff and visitor experience through ease of locating their destination quickly and easily, (b) Improved accessibility management through clear understanding and communication of accessible pathways and (c) Capacity to publicise the availability of university facilities and destinations, such as food services, galleries, public clinics, bank outlets (ATMs), bookable facilities, etc. Within the wayfinding project, another issue was the differing skill sets of the members, i.e. some had technical expertise, others portrayed conceptual prowess, business strategic thinking and others were in effect the ultimate customer i.e. FMU. To address such issues, CoP members decided to share their knowledge both in meetings and at workshops e.g. in the use of Revit software. The wayfinding 
project was in essence a proof of concept about the CoP in that it would verify the direction of the CoP, develop an understanding of each of the members' specialty areas and thus foster an arena of trust and mutual respect where the subject matter could flourish with minimal impediments. However, given the differentiating factor of a CoP being about knowledge gained rather than undertaking a job at hand, it is important to note that the way finding project was a project created by the CoP members, and not from an exogenous force. Due to time constraints, the wayfinding project has yet to be completed, but it is envisaged that this should be in the near future. Finally, part of the process of addressing issues was reflection on the CoP as a whole and, in effect, the paper presented here is the output of such a process and is a vehicle for the members to reflect over the CoP existence, assess the CoP's goals, effectiveness and future directions.

\subsection{Expansion}

To expand the $\mathrm{CoP}$, it is critical that the seed planted in the pilot wayfinding project is grown and penetrates throughout FMU, and that it is seen to be an integral part of FMU operations. From such a positive position, it may well be possible then to lever additional funds, time and commitment for extra personnel to allow the use of spatio-temporal information to percolate into other areas of FMU to begin with, but ultimately to other areas of the university and become embedded in many university business processes. UniSA promotes industry engagement and orientated teaching and the use of BIM within this context is highly applicable as more firms involved with buildings move towards the incorporation of BIM into their workflow. Therefore, it is imperative that the university reflects this trend and thus incorporates the skill sets of its researchers into the teaching environment. As such, to achieve such an expansion to the BIMGIS CoP, the leaders of the respective teaching areas will need to engage in dialog to assess how to further incorporate spatio-temporal into teaching, and in doing so assess existing teaching capabilities e.g. the possibility of experts teaching across schools and divisions whilst simultaneously reviewing degree programs to assess where such courses/subjects/modules could fit. Such programs that need to assess the impact of BIM-GIS could include Engineering, Property, Planning, Surveying (e.g. 3D cadastre) and Environmental. To reflect the combined nature of spatiotemporal, as opposed to separate BIM and GIS, there could be moves towards an underpinning first year course introducing the philosophy of spatio-temporal activities that could then be streamed thereafter in subsequent courses. This would engender an environment where the students cannot only 'do' spatio-temporal activities but have the ability to think critically about the direction in which such learning/ doing should go. The $\mathrm{CoP}$ will periodically review its Raison d'être for, as the expansion of BIM-GIS goes more mainstream, it may begin to become more project management led and thus leave the confines and essence of being a CoP.

\section{Conclusion}

The BIM-GIS CoP brought together staff within UniSA that believed commonalties existed and that opportunities could be realised for UniSA's 
operational business activities as well as teaching and research. The voluntary and egalitarian nature of a $\mathrm{CoP}$ lent itself to such an environment where staff were pursuing collaborative efforts within BIM-GIS, up and above their normal targeted work outputs. The CoP members displayed varying standpoints and aspirations but displayed a consensus that BIM-GIS collaboration was advantageous. Initially, variance seemed to stem from the natural affinity with respective working environments, namely Architecture, Construction and FMU focused more on the built building environment (possibly constituting an 'interior' view), whereas Geospatial - especially with the prefix of 'Geo' i.e. meaning Earth, portrayed a more 'global' exterior view. However, through CoP discussions, members soon formed the collective opinion that as both BIM and GIS capture/create, store, manage, analyse and present data, it's not so much a collaboration of BIM and GIS or BIM $v$ GIS, it is more of a blurring of scale, as they are both are concerned with spatio-temporal relationships whether that be in a building or outside or both. The CoP has engendered a social learning arena where disciplines and hierarchies have been transcended, but it has not been without its challenges. Having sufficient time continues to be the premier bane of the BIM_GIS CoP, especially when competing interests come to the fore that result in other management led and project oriented tasks taking priority. Nevertheless, the worth of the social learning contained in the $\mathrm{CoP}$ enables the community to move forward, albeit not at the pace that Wenger [4] envisaged. A successful wayfinding project could be a critical component in the expansion of the $\mathrm{CoP}$, as it could showcase not only the BIM-GIS collaboration but also how this was efficiently and effectively achieved through the use of a CoP. Consequently, the worth of using the $\mathrm{CoP}$ approach to multi-disciplinary research can be further acknowledged and endorsed as a valuable, worthwhile and effective method.

\section{References}

[1] Bergin, M.S. A Brief History of BIM http://www.archdaily.com/302490/abrief-history-of-bim/

[2] Tomlinson, R., Thinking about GIS: Geographic Information System for Managers, 3rd edn, ESRI press, Redlands, United States, 2007.

[3] Corcoran, P.A., Spatial information accessibility in South Australia from the Internet: a national comparison. Journal of Internet Business, 10, 2012.

[4] Wenger, E.C., Communities of Practice: Learning, Meaning and identity, Cambridge University Press, Cambridge, 1998.

[5] Foresman, T., (ed) The History of Geographic Information Systems: Perspectives from the Pioneers, Prentice Hall, 1997.

[6] Maruyama, M., Academic concept inbreeding, failure of interbreeding, and its remedy by outbreeding. Human Systems Management, 17 pp. 89-91, 1998.

[7] Moffat, S. \& Kohler, N., Conceptualizing the built environment as a socialecological system. Building Research and Information, 36(3), pp. 248-268, 2008. 
[8] Wenger, E.C., McDermott, R. M. \& Snyder, W.M., Cultivating communities of practice, Harvard Business School Press, New York, 2002.

[9] Pfeffer, J., The Human Equation: Building Profits by putting people first, Harvard Business School Press, Boston, Massachusetts, 1998.

[10] Lave, J. \& Wenger, E.C., Situated learning: Legitimate Peripheral Participation, Cambridge University Press, Cambridge, 1991.

[11] Wenger, E.C., Learning as a social practice. Knowledge Management Review, 6, pp. 30-32, 1999.

[12] Elmualim, A.A. \& Govender, K., Communities of Practice (CoP) in UK Large Contracting Firms: Contrasting Application and Non-utilized Merits. Architectural Engineering and Design Management, 4(3), pp. 149-159, 2008.

[13] Peltonen, T. \& Lamsa, T., Communities of practice and the social process of knowledge creation: towards a new vocabulary for making sense of organisational learning. Problems and Perspectives in Management, 4, 2004.

[14] Thompson, M., Structural and Epistemic Parameters in communities of practice. Organisational Science, 16, pp. 151-164, 2005.

[15] Hislop, D., Knowledge management in Organisations, Oxford University Press, New York, 2005.

[16] McGinley, T., A morphogenetic architecture for intelligent buildings. Intelligent Buildings International, 7(1), pp. 4-15, 2015.

[17] McGinley, T. \& Fong, D., DesignGhosts: Mapping User behaviour in BIM, CAADRIA 2015, in press 2015.

[18] Aamodt, A. \& Plaza, E., Case-based reasoning: Foundational issues, methodological variations, and system approaches. AI communications, 7(1), pp. 39-59, 1994.

[19] Corcoran, P.A. \& Bruce, D.A., University 'Mapping' Education in Australia: a Confusing Exposure? Proceedings of the International Cartographic Conference, ed M.F. Buchroithner. Dresden, 2013.

[20] Robinson, A.H. Elements of Cartography, 5th edn, Wiley, New York, 1984.

[21] McDougall, K., Williamson, I., Bellman, C. \& Rizos, C., Challenges Facing Spatial Information and Geomatics Education in the Higher Education Sector', Combined 5th Trans Tasman Survey Conference \& 2nd Queensland Spatial Industry Conference, Cairns, 2006. 